\title{
¿A qué nos referimos cuando hablamos de “usar la lengua para aprenderla”?
}

\section{Ernesto Martín Peris,} Grup de Recerca sobre aprenentatge i ensenyament de llengües (Grael, Universitat Pompeu Fabra, Barcelona, España)

\section{Introducción}

El concepto de "aprendizaje de la lengua mediante su uso” ${ }^{1}$, aplicado a las prácticas de aula en la enseñanza de lenguas extranjeras (en adelante, L2) ha experimentado en los últimos años una notable evolución, debida principalmente al desarrollo de los estudios del análisis del discurso y de las teorías de la psicología del conocimiento y aprendizaje —el socioconstructivismo y, en su aplicación a al aprendizaje de segundas lenguas, la teoría sociocultural, tal como la proponen, entre otros, Lantolf (2000) o van Lier (1996) — . El contenido de esta conferencia consistirá en presentar y comentar algunas de las repercusiones que, a nuestro juicio, esta nueva — dobleperspectiva sobre la lengua y sobre su aprendizaje comporta para las prácticas del aula.

En nuestra cultura educativa se ha concebido tradicionalmente el aula como un lugar en el que los alumnos reciben un compendio de informaciones que deben almacenar en sus mentes en forma de conocimiento; para llevar a cabo las actividades propias del aula no se consideraba que el uso del lenguaje constituyera un elemento decisivo, más allá de ser el medio principal del que se servía el profesor en su transmisión de informaciones y de instrucciones. Es cierto que esta concepción del aula se ha visto sustancialmente modificada, pero también lo es que una cierta inercia contribuye a mantener el estado de cosas anterior, al menos parcialmente. Sin embargo, el lenguaje y la interacción, como mediadores del desarrollo del conocimiento, están empezando a desempeñar un papel importante en los nuevos enfoques de la enseñanza. Conviene, por tanto, explorar las formas en que el uso del lenguaje y su relación con la acción del discente contribuyen de manera más eficaz a ese desarrollo del conocimiento. En ese sentido, la investigación que, mediante diversos proyectos, se está llevando a cabo en los departamentos que organizan estas jornadas es importante y de largo alcance.

En esa tradición a la que me he referido, el aula de lenguas extranjeras constituye en cierto modo un caso aparte, pues esta fue siempre concebida como una especie de palestra en la que los alumnos ejercitan sus habilidades para desenvolverse en la L2. Desde los inicios del Método Directo se proclamó que hablar una lengua es una habilidad y que estas se desarrollan 
mediante su ejercicio, y no mediante el estudio o la observación de sus características. La novedad de nuestra situación actual radica precisamente en una profundización y enriquecimiento de los conceptos de "uso de la lengua” y de "habilidad" para llevar a cabo ese uso.

En efecto, las interpretaciones que se han dado a ese concepto a lo largo de la historia de la metodología de la enseñanza de segundas lenguas han sido variadas y no homogéneas. En primer lugar, hay que señalar que, hasta la difusión de estas nuevas teorías sobre la lengua y su aprendizaje a las que me he referido, con el término de "uso de la lengua" se aludía exclusivamente a la lengua objeto de aprendizaje (L2), puesto que la presencia de otras lenguas en el aula se consideraba, más que un medio, un obstáculo para ese aprendizaje; hoy no es así, y si se habla de usar la lengua en el aula, se incluye de forma importante y no marginal el uso de la lengua propia (L1) de los alumnos, el de otras lenguas vehiculares que puedan suplir la ausencia de una L1 común y, por supuesto, el uso de la lengua objeto de estudio. De hecho, se está más próximo al concepto de "uso del lenguaje” que al de uso de una lengua determinada (lenguaje verbal, se entiende, pero sin olvidar —y esto resulta crucial- que el lenguaje verbal se usa siempre en combinación con otros sistemas semióticos, con otros lenguajes, tanto dentro del aula como fuera de ella: usar la lengua, por lo tanto, será siempre usarla junto con esos otros lenguajes). Las últimas teorías acerca del plurilingüismo como una competencia de las personas, así como las referentes a la intercomprensión de lenguas próximas, no hacen sino apoyar esta visión de los humanos como usuarios del lenguaje, en sus múltiples variaciones.

En segundo lugar, el concepto de "usar” la lengua para aprenderla se equiparaba de forma automática al de "hablar” la lengua para aprenderla, reduciendo así ese concepto, en gran medida, a los usos meramente productivos y orales, y dejando aparte los escritos y especialmente- los receptivos. Esta afirmación no equivale a decir que la didáctica de segundas lenguas descuidara el desarrollo de las habilidades receptivas y de la lengua escrita; más bien remite a los procesos de uso en el aula que se suponían motores del aprendizaje, entre los que destacaba de forma casi exclusiva el de la comunicación oral ${ }^{2}$. Sin restar importancia a este eje fundamental de los procesos de aprendizaje de segundas lenguas, conviene completarlo considerando cuál es la verdadera naturaleza de la comunicación realizada en una L2 en el aula y si esa naturaleza es de carácter exclusivamente productivo.

Otra novedad, en relación con el uso de la lengua y su aprendizaje, procede de las teorías psicológicas sobre el conocimiento y su relación con el lenguaje. Postula L. S. Vigotsky (1978) 
que todo desarrollo del conocimiento se origina en la acción, y más en particular en la interacción social; según los seguidores de este psicólogo, las metáforas del “input”, de la “caja negra” o del “dispositivo de adquisición del lenguaje” no son las más afortunadas para explicar el aprendizaje de una lengua, puesto que no incluyen el componente de la acción del sujeto que aprende ni la de los que se encuentran en su contexto próximo; como alternativa a esas metáforas proponen la de "mediación del conocimiento": es a través de la actividad social como esas capacidades que un individuo de la especie humana posee por su dotación genética, se modifican y se reorganizan en formas superiores de conocimiento, al tiempo que le permiten ejercer un control consciente sobre sus propias actividades mentales.

Consecuentemente, el lenguaje, herramienta fundamental para la interacción social, se convierte en una herramienta al servicio de la organización y el autocontrol del pensamiento del individuo. En el caso del aprendizaje de lenguas, se produce una particular circunstancia, pues el desarrollo de la herramienta mediadora del aprendizaje y el desarrollo del propio objeto de aprendizaje vienen a coincidir en una misma realidad, es decir, la lengua. Más aún, y de manera especial en el aprendizaje de una L2, la distinción entre “conocimiento” y “uso” se diluye, puesto que el conocimiento no cabe definirlo sino en términos de uso, y es justamente el uso de la lengua el que crea su conocimiento. A este respecto es interesante la propuesta de un lingüista como Halliday (1993), quien, desde la lingüística sistémico-funcional, propone una teoría del aprendizaje basado en la lengua: el paralelismo y la complementariedad entre las teorías sobre el lenguaje propuestas por una escuela de psicología (Vigotsky) y una de lingüística (Halliday) han sido puestas de relieve por Wells (1994).

La interacción verbal, pues, como forma primigenia de la mediación del conocimiento, hace concebir todo aprendizaje — también el de una L2 - como una forma de diálogo. Si existe un dispositivo de adquisición del lenguaje, este no se encontrará en el cerebro de las personas, sino en su interacción con los demás, como se afirma en la teoría sociocultural. Si se da adquisición de una segunda lengua, no es como un efecto posterior de una interacción llevada a cabo en esa lengua: esa misma interacción es la adquisición. Por eso, autores como Lantolf o van Lier prefieren hablar de “participación” más que de “adquisición”; es en la participación en prácticas sociales donde se genera un dominio de nuevas formas lingüísticas, que primero se utilizan con el apoyo de los otros participantes en esas prácticas y así se van interiorizando hasta que llegan a poder usarse de forma autónoma; al mismo tiempo, es esa participación la que 
facilita la regulación del propio comportamiento y, en definitiva, la autorregulación del aprendizaje.

Sintetizando, pues, estos nuevos planteamientos, podemos referirnos al uso de la lengua en el aula desde una triple perspectiva:

- Como la ejercitación de la competencia comunicativa en la L2; obviamente, se trata del uso de esa L2.

- Como un medio para la gestión de las diversas actividades del aula; esto puede suceder tanto en L2 como en L1 u otra lengua vehicular que facilite esa gestión.

- Como medio para la construcción conjunta de conocimientos; también en este caso la L1 u otras lenguas vehiculares, en las que los alumnos poseen un mayor dominio, pueden sustituir a la L2 en el ejercicio de esa función (aunque no necesariamente).

Este nuevo enfoque modifica no solo el concepto de interacción en el aula y de su relación con el aprendizaje, sino que también confiere a la L1 y a otras lenguas un papel y una función decisiva en el aprendizaje de una L2. Huelga decir que, en la medida en que el dominio de la L2 lo permita, su uso para los tres aspectos arriba señalados resultará muy beneficioso para el aprendizaje; pero al mismo tiempo, cuando este dominio, a causa de su pobreza o sus limitaciones, suponga un obstáculo al logro de la comunicación en la gestión de las actividades del aula o en la construcción conjunta de conocimientos, el recurso a otras lenguas será perfectamente recomendable y en absoluto rechazable.

En lo que sigue de mi conferencia presentaré algunos puntos que considero de interés en relación con el primero y el tercero de estos tres aspectos, y no abordaré el segundo, en espera de mejor ocasión.

\section{El uso de la lengua en contextos ajenos al aula}

Para tratar este tema me detendré en algunas de las propiedades que caracterizan el uso de la lengua fuera del aula. En efecto, si nos remitimos a lo que he señalado anteriormente, en relación con usos no solo orales y no solo productivos de la L2, procede disponer de modelos de esos usos en cuya competencia se pretende progresar. En otras palabras: ¿Qué entendemos por uso de la lengua cuando este se produce fuera del aula? ¿Cómo se lleva a cabo ese uso? ¿Qué variaciones presenta? 
Adoptando uno de los conceptos propios de los estudios del análisis del discurso, podemos definir el uso de la lengua como la participación en prácticas discursivas sociales. Esa participación no consiste simplemente en hablar o escribir, sino que adopta formas, convenciones y reglas muy distintas a tenor de los diferentes géneros de discurso propios de cada una de ellas. Observemos en dos ejemplos estas reglas de participación.

Podemos pensar, en primer lugar, en una celebración o fiesta importante que se avecina en el seno de una familia. En nuestra sociedad actual, tal circunstancia da lugar a una práctica social, consistente en la notificación de la novedad y la correspondiente invitación al círculo de amistades y familiares. ¿Cómo se desarrolla esa práctica social? Básicamente podemos afirmar que la práctica se inicia cuando la familia protagonista envía algún tipo de mensaje a quienes ha seleccionado como destinatarios, continúa con la recepción del mensaje por estos y finaliza con la respuesta que en cada caso se considere apropiada.

Prescindamos de las dos últimas partes y concentremos nuestro análisis en la elaboración del mensaje que envía la familia protagonista. La primera opción que tiene ante sí el emisor de este mensaje es la del género que va a adoptar para formularlo; en principio podría elegir entre una gran cantidad de ellos: podría escribir una carta convencional, o tal vez un telegrama, o un SMS; podría publicar un post en su blog, o hacer imprimir unos tarjetones; podría tal vez realizar una llamada telefónica, poner un anuncio en la prensa local...; su conocimiento de las convenciones culturales le permitirá realizar sin riesgo la elección adecuada en cada caso. Obsérvese que en algunos casos será obligado el recurso a más de un género: llamada telefónica o correo electrónico más tarjetón impreso; visita personal para entregar en mano el tarjetón; nota personal y manuscrita en el mismo tarjetón impreso, dirigida a su receptor, etc. Realizada esta opción, quedan aún muchas otras que tomar, en relación con la elaboración del mensaje. Habrá que decidir acerca del tono que se quiere adoptar en la formulación lingüística — de acuerdo con una serie de variables_-, elegir los recursos lingüísticos que le confieran ese tono al mensaje, etc. Todo esto lo ha explicado muy bien la lingüística moderna.

Quisiera, sin embargo, destacar un aspecto, tratado también tradicionalmente en los estudios de lingüística dentro del componente paralingüístico, y al que algunos autores se refieren modernamente como multimodalidad de la comunicación. Es un componente al que en mi opinión la enseñanza de lenguas ha prestado insuficiente atención y al que, sin embargo, tanta atención prestarían quienes se hallaran en la situación que hemos adoptado como ejemplo. Pensemos en la cantidad de aspectos que hay que tomar en consideración en la escritura —por 
ejemplo - de un tarjetón para invitar a una boda: desde la forma, el color, la consistencia y textura del papel que le sirve de soporte, hasta el tipo y tamaño de letra y los posibles adornos gráficos, la distribución del texto en la superficie del papel, etc. La enseñanza de lenguas más moderna se concentraría en las expresiones lingüísticas más apropiadas para el tono que se decidiera adoptar, las fórmulas para expresar invitaciones, las convenciones de tipo sociocultural en relación con la información sobre listas de boda y otras prácticas similares, etc. Pero una comunicación eficaz, en todos los sentidos de la palabra, exigiría no detenerse ahí, para poder asegurar que se ha participado plenamente y a satisfacción en la práctica social.

Como segunda muestra, tomemos una de las nuevas prácticas, propias de la comunicación realizada gracias a los medios tecnológicos. Pensemos, por ejemplo, en la participación en un foro de Internet. En uno de esos foros, concretamente en el Foro de Profesores del Centro Virtual del Instituto Cervantes, apareció recientemente una intervención con el siguiente título: "Re: el cuento más corto del mundo”3 ; abierto el mensaje, en su contenido podía leerse un cuento brevísimo que el autor ofrecía a los otros miembros del foro; intervenía en respuesta a un mensaje previo en el que se pedía la referencia sobre "el cuento más corto del mundo para poderlo trabajar con alumnos de segundo básico”. El cuento ofrecido por este forista decía así: “Agosto. Rodas. Piel. Piel. Adiós”.

Podríamos caracterizar esa práctica social como una "tertulia digital espontánea asíncrona”; en efecto, los participantes de ese foro se comportan aproximadamente de la misma forma en que lo harían en una tertulia presencial: interviniendo discrecionalmente cuando les apeteciera, prestando una mayor o menor atención a las palabras de los distintos compañeros de tertulia, etc.; así, habrá quienes se limiten a leer una de las intervenciones del foro sin darle respuesta, quienes decidan escribir una respuesta y luego abandonar la participación, y habrá quienes decidan enzarzarse en sucesivas intervenciones cruzadas con las de otros foristas, creando así la tertulia digital.

La primera fase de la participación consiste en el acceso a uno de los mensajes; para ello, los foristas habrán leído previamente una pantalla en la que aparece la lista de intervenciones en la que aquel se inserta. Estas listas tienen una configuración y estructura propias, sencillas y escuetas, pero sin cuyo conocimiento no es posible intervenir de forma eficaz; en efecto, hay que saber distinguir el tema del mensaje, saber si es primera intervención o si es respuesta a una intervención anterior, reconocer aquellos que forman un hilo de continuidad, etc. Para completar eficazmente esta primera fase de la participación, los foristas habrán realizado un primer uso de 
la lengua: leer en una lista y seleccionar un elemento; al margen de las habilidades estrictamente relacionadas con el manejo de las necesarias herramientas informáticas, no es preciso insistir en tres aspectos importantes de las capacidades necesarias para efectuar este uso: a) es necesario un mínimo conocimiento de la lengua en que está escrita la lista; (b) ese conocimiento no precisa ser completo y exhaustivo (ni desde el punto de vista léxico, ni del morfológico o el sintáctico); (c) ese conocimiento no es suficiente: es preciso tener el dominio de otros procedimientos y otros códigos (en particular, de los que regulan la estructura de la lista y del contenido informativo que puede aparecer en los distintos apartados de cada registro de la lista).

En relación con el tema que nos ocupa, destaquemos que la acción ejecutada por un forista hasta este momento en el que pulsa la tecla que le va a abrir el mensaje de su interés es una actividad de uso de la lengua: no ha producido ningún sonido ni ha escrito ningún signo, pero ha tomado una decisión basada en una información que ha obtenido gracias a la lengua; es, por otra parte, un uso comunicativo lleno de sentido y que responde a una necesidad muy concreta del sujeto. Si pensamos en un aula de L2 y nos imaginamos una práctica equivalente, podemos afirmar sin lugar a dudas que no es necesario esperar a que los alumnos produzcan un enunciado para saber que están usando la L2. La conveniencia de que, por razones pedagógicas, los alumnos manifiesten algún tipo de respuesta que permita asegurarse de que ese uso receptivo y silencioso se ha producido no debe impedirnos reconocer plenamente la naturaleza del uso en sí mismo. A mi entender, esto abre muchas posibilidades a la práctica de los usos de la L2 en el aula, que se aproxima a la que proponen las conocidas tesis de las teorías de ASL sobre la importancia del input para la adquisición de una L2, pero que va mucho más allá de ellas; en efecto, no se trata únicamente de input, más o menos rico o comprensible, sino de verdadero uso interactivo de la L2.

En segundo lugar, y cuando se haya abierto la pantalla con el mensaje, el forista se encontrará ante un texto complejo; complejo y compuesto: en efecto, aparte de la superestructura propia de este género (el mensaje de correo electrónico), cuyo conocimiento le permitirá interpretar el mensaje en sí mismo, el texto tiene dos partes bien diferenciadas: por un lado una respuesta a una intervención de otro forista, por otro un cuento, acompañado de un comentario de su propio autor.

Nos hallamos, por tanto, ante dos muestras: la muestra de un género de gran fuerza funcional (un mensaje de correo electrónico) y la muestra de un género de ficción: un cuento. Serán, por tanto, bien diferenciadas la formas de uso de ambos géneros y las formas de 
participación en ellos, por más que ambas consisten en la lectura en pantalla de texto impreso. Sin ánimo de ser exhaustivos en el análisis de estas formas de participación, detengámonos en dos detalles:

- El uso significativo de ambos textos por parte de un forista puede limitarse a la lectura; esta lectura podrá tal vez desencadenar otras posibles lecturas (de otras intervenciones en esta tertulia, por ejemplo), pero no comporta necesidad alguna de producción para ser un uso auténtico y significativo.

- El lector puede también optar por extender su participación más allá de la lectura y escribir un mensaje de intervención en el foro.

En esta segunda forma de participación pueden darse también diversas opciones: el contenido de la intervención puede limitarse a un texto orientado a la relación interpersonal con el autor del mensaje (por ejemplo, felicitándolo por su cuento, o agradeciéndoselo, o con algún otro tipo de “acto de habla”); puede también ofrecer información sobre otros cuentos "más cortos del mundo”, aludiendo al tan famoso de Augusto Monterroso sobre el dinosaurio; puede decidir aportar su propio cuento, emulando al forista anterior, etc. Los foristas que opten por intervenir con la escritura de un mensaje deberán activar un conjunto de competencias, a las que aquí no vamos a referirnos, pero en las que destacaremos que desempeña un papel importante la representación de sí mismos que quieran que el mensaje refleje, y la relación que deseen establecer con el destinatario y los lectores en general. En todos los casos, el dominio de la lengua requerido para el logro de los objetivos deseados consiste en algo más que un buen conocimiento del vocabulario, la gramática y las estructuras textuales.

Volviendo a los lectores que hayan decidido no intervenir con la escritura de un mensaje, observemos más de cerca lo que se les ofrece en el texto de lectura y su participación en él. Podemos proceder sirviéndonos de la división de los usos de la lengua en transaccionales (intercambio de información), interpersonales (relación entre los interlocutores) y estéticos (aprovechamiento de los recursos del código); son tres vertientes que suelen darse combinadas en un mismo texto, con mayor predominio de una de ellas. Lo interesante aquí es la presencia destacada del uso estético en una de las partes del mensaje. El autor ha decidido escribir un cuento y brindárselo a sus posibles lectores, confiado en las competencias que estos tienen para interpretarlo correctamente. Entre esas competencias figura el conocimiento (implícito, no necesariamente explícito) de los géneros de discurso, de su estructura. Así que en un cuento el lector espera encontrar una situación espacio-temporal, unos personajes y unos hechos, y un 
desenlace de esos hechos; es lo que le ofrece este breve texto, siempre que el lector disponga de otros conocimientos adicionales. En efecto, el tiempo es, evidentemente, agosto, y el lugar, Rodas; ambas referencias, sin embargo, contienen elementos informativos que no se reducen a lo meramente espacio-temporal: agosto es, en la cultura de la Europa occidental y de las sociedades contemporáneas, el mes del veraneo por excelencia (y este del veraneo es otro concepto no estrictamente cronológico), lo cual crea en los lectores del cuento unas determinadas expectativas en cuanto a los posibles acontecimientos, mientras que excluye otros como muy improbables, si no imposibles. Rodas, por su parte, no es simplemente una isla griega en el Mediterráneo: es destino habitual de numerosos viajes de veraneo. Los hechos vienen a continuación de la localización espacio-temporal, concentrados en la secuencia “piel-piel”, que todo lector competente interpreta como la referencia a dos pieles distintas y en contacto (humanas y en alusión a los cuerpos como sinécdoque); para expresar este contacto, el autor renuncia a la formulación de una proposición lingüística y opta por reproducir en la materialidad del texto, mediante la proximidad de las dos palabras, la proximidad de los cuerpos aludidos. El acontecimiento de un encuentro sexual se expresa concentrado en esta yuxtaposición de dos términos, del mismo modo que lo efímero de la relación queda relatado por la última palabra del texto.

Estamos, pues, ante un texto completo, cuya interpretación viene posibilitada por los diversos conocimientos que tenga el lector: generales del mundo, particulares del género de discurso, lingüísticos sobre el vocabulario. Un texto carente prácticamente de sintaxis, pero no por ello menos texto. No solo eso: si alguien quisiera reponer esa sintaxis ausente, podría dar entre otras con una frase como esta: "En el mes de agosto y en la isla de Rodas tuvieron una fugaz aventura amorosa”, la cual difícilmente podría ser considerada como un cuento por ninguno de los lectores. Lógicamente podría formar parte de un cuento, una novela u otro tipo de relato, pero se nos aparece como un mensaje incompleto.

En síntesis: muchos de los usuarios de la lengua que intervienen en un foro como este lo hacen exclusivamente de forma receptiva; en la lectura e interpretación de los mensajes que encuentran, activan un conjunto de habilidades y conocimientos que les permite relacionar el contenido de los mensajes con sus intereses personales y satisfacer así unas determinadas necesidades. El componente estético del lenguaje desempeña un papel importante (cuando no fundamental) en la satisfacción de esas necesidades que — señalémoslo— no son “necesidades 
de supervivencia en la vida cotidiana”, pero no por ello son menos importantes ni hacen que el uso de la lengua sea de menor implicación e intensidad.

\section{Repercusiones para el uso de la lengua en el aula}

En primer lugar podríamos mencionar la importancia de los usos estéticos. Estos fueron desterrados del mundo del aula de L2 por una especie de pecado original en los albores de la metodología, cuando el Método de la Gramática-traducción recurría de forma casi exclusiva a textos literarios en lengua escrita; por otra parte, el objetivo de los alumnos que se matriculan en nuestras clases no es primordialmente entender la poesía que se escribe en nuestra lengua, y mucho menos ser escritores en ella. Lo cierto es, sin embargo, que si se parte del supuesto de que el uso es aprendizaje, será importante explorar lo que cada uno de los tipos de uso puede aportar a ese aprendizaje, y muy en particular lo que puede aportar el uso estético, realizado de forma predominantemente receptiva.

En este sentido, el concepto de uso significativo, su relación con las competencias generales de la persona (y en particular la del "saber ser”) que propone el Marco Común Europeo de Referencia (MCER 2001), y la idea de la implicación de la globalidad de la persona (y no solo de su dimensión intelectual o racional) en el uso de la lengua, permiten vislumbrar una fuerza especial en los usos estéticos, que los hacen especialmente recomendables en el aula de L2.

La idea de la recepción (lectura, comprensión e interpretación de textos orales o escritos) como actividad de uso plena de sentido, sin que conlleve necesariamente actividades de producción, permite pensar en tareas de aprendizaje que integren plenamente los usos estéticos, partiendo de ellos y explotando en ellos los procesos de aprendizaje activados por el uso.

Otro aspecto de particular interés puesto de relieve por el análisis crítico del discurso y por los estudios de literacidad crítica es el del uso crítico del lenguaje. Si bien estas disciplinas se han centrado en el discurso en L1, nada impide incorporar sus supuestos al estudio del discurso en L2 y su relación con el aprendizaje. El ciudadano del mundo actual vive inmerso en un mar de discursos que lo rodean, lo acosan y lo distraen. Ser un usuario competente de una lengua requiere ser un usuario crítico. No me extenderé sobre este punto, simplemente lo recojo aquí por el relieve que está adquiriendo en la actualidad y porque en nuestro Departamento se está 
llevando a cabo un proyecto de investigación sobre este tema y su relación con la formación lingüística ${ }^{4}$.

El carácter reflexivo es otra de las propiedades del uso de la lengua en el aula que quisiera destacar. Gracias a él, la conciencia lingüística adquiere un importante peso específico en los procesos de comunicación y de aprendizaje. Las condiciones en que se desarrolla la interacción en el aula permiten mantener tenso el hilo de la atención al significado de los mensajes mientras se atiende a aspectos formales y funcionales de los mismos; es lo que algunos autores llaman el "doble foco" (ver Bange, 1992): foco en el sentido, foco en la forma. Las condiciones de interacción en el mundo externo al aula imponen una presión sobre el contenido del mensaje que relega a un segundo lugar cualquier consideración sobre la forma que no esté directamente vinculada a la negociación de ese sentido; en el aula, por el contrario, es posible mantener conversaciones en las que la atención a la forma sea legítima por sí misma.

La multimodalidad es el último de los aspectos sobre los que quería hacer hincapié. A mi juicio, las prácticas de aprendizaje en el aula se han visto tan absorbidas por el componente lingüístico de la comunicación que han dejado desatendido este componente multimodal, inherente a todo uso del lenguaje y cada vez más presente en las sociedades modernas de la comunicación audiovisual. Ejercitarse en el aula en el uso de la lengua, mutilando este uso de uno de sus integrantes, es ejercitarse en falso. Aparte de eso, el carácter multimodal de la comunicación ofrece un extraordinario andamiaje al déficit en el dominio de las formas lingüísticas.

Para finalizar esta primera parte podría proponerse una clasificación de las distintas formas de participación de un alumno de L2 en prácticas discursivas sociales. Una primera distinción es la que puede hacerse entre ser un miembro activo que interviene en un evento o ser un observador externo de ese evento. Los observadores externos reciben e interpretan mensajes que en primera instancia no van dirigidos a ellos: pueden mantenerse al margen de la interacción que se produce. Los observadores externos de un evento son prototípicamente los receptores de géneros de ficción, tanto textuales (novela, poesía) como escénicos (teatro) o audiovisuales (cine y televisión).

Los participantes en un evento reciben y pueden emitir mensajes dirigidos a ellos en primera instancia, y su participación puede darse, a su vez, bajo diversas formas:

a) En interacción con otros miembros (en producción y recepción imbricadas de mensajes (de forma reglamentada o espontánea: coloquios, charlas, entrevistas, tertulias...). 
b) Como emisor del mensaje: alocuciones orales o mensajes escritos, dirigidos a unos destinatarios que pueden ser individuales o colectivos, conocidos o desconocidos, específicos o indeterminados, presentes o ausentes, etc.

c) Como receptor de mensajes, con propiedades correlativas a las de la emisión.

\section{El uso de la lengua en el aula como la mediación del aprendizaje}

El otro aspecto del uso de la lengua en el aula que destacábamos en la introducción a esta conferencia es el que se relaciona con la mediación social del aprendizaje. Una primera aproximación a este concepto, en el campo de la enseñanza de lenguas, es la que se dio en las propuestas de desarrollo de la autonomía y de “aprender a aprender” que surgieron hacia los años 80 del siglo pasado. En las actividades relacionadas con estos nuevos objetivos de aprendizaje el aula se convertía en un espacio de comunicación (entre profesor y alumnos, así como entre los propios alumnos) cuyo tema y acción no era la participación en prácticas sociales como las que se han tratado en la sección precedente, sino el desarrollo del propio proceso de aprendizaje y las estrategias con que cada alumno lo llevaba a cabo.

El Marco común europeo de referencia, en su introducción al capítulo 2, contiene un breve párrafo que sintetiza el enfoque adoptado, un “enfoque orientado a la acción”. Tras afirmar que, en el aprendizaje y uso de la lengua, las personas “desarrollan una serie de competencias, tanto generales como competencias lingüísticas comunicativas en particular”, concluye: "El control que de estas acciones tienen los participantes produce el refuerzo o la modificación de sus competencias”. A mi entender, en esta última frase se ofrece una reformulación del concepto de aprendizaje (esto es: “el refuerzo o la modificación de sus competencias”), y la posibilidad de que tal aprendizaje se dé se condiciona al hecho de que el control de las acciones con que se lleva a cabo esté en las manos del alumno.Creo que lo que aquí se afirma supone una nueva perspectiva sobre la función del profesor y de los alumnos, que profundiza y amplía los conceptos de autonomía y de aprender a aprender; o, al menos, la forma en que estos conceptos habían sido trasladados a la práctica en la formación de profesores y en la elaboración de materiales. En efecto, no se trata únicamente de que los alumnos adquieran unas técnicas y estrategias más eficaces en su estudio de la lengua, ni de que al finalizar el currículum estén equipados para continuar de forma autónoma el aprendizaje de la L2 (un proceso que 
puede prolongarse durante toda una vida). Se trata de que el profesor transfiera el control del proceso al alumno, para que ese proceso sea eficaz aquí y ahora.

En la base de esta propuesta se halla la tesis vigotskiana referente a que todo proceso mental de orden superior tiene lugar en dos momentos distintos: en un primer momento, el proceso se origina en el exterior del sujeto, mediante su interacción con otro sujeto más competente; esta interacción le permite realizar algo que, abandonado a sus propios medios, sería incapaz de llevar a cabo y, en esa ejecución apoyada en una cooperación externa, el sujeto va interiorizando y apropiándose de los recursos necesarios para llegar a ejecutar el mismo proceso de forma autónoma. El proceso ha sido explicado por Bruner (1966) con la conocida metáfora del andamiaje, y en su aplicación al aprendizaje de L2 diversos autores han explorado sus posibilidades.

El análisis del discurso del aula ha puesto de relieve la forma en que los alumnos construyen conjuntamente el conocimiento, hasta el punto de que la metáfora del andamiaje del interlocutor más experto ha evolucionado hacia la de un andamiaje basado en la interacción lingüística; del mismo modo, se considera que la importancia de este fenómeno radica más en la fuerza que el andamiaje posee per se que en la cualidad de más experto de quien lo suministra; en este sentido resultan especialmente interesantes las aportaciones de, entre otros, Donato (1994) o Lantolf (2000), cuando hablan de “andamiaje entre iguales”; o las de Van Lier (1993), cuando observa cómo el andamiaje no es un mecanismo estático sino un proceso dinámico que surge a iniciativa del menos experto y se desarrolla a tenor de sus requerimientos. Este autor señala cuatro tipos de interacción del alumno en el aula: con otros más expertos (el profesor), con otros compañeros de su mismo nivel, con otros compañeros de nivel inferior ("al enseñar, se aprende”), y consigo mismo, con sus propios recursos internos.

Una línea de investigación que está siendo explorada también con interesantes perspectivas es el discurso interno, aquel mediante el cual una persona se ayuda en la ejecución de una acción que le resulta de una especial complejidad o dificultad; mediante la verbalización de las sucesivas operaciones que está realizando o ha de realizar, la persona domina mejor su propia acción; o bien, mediante la repetición mental o casi silenciosa de frases y estructuras, se las apropia mejor y las retiene con más eficacia.

Son diversos los autores que han dedicado su atención al discurso del aula ${ }^{5}$. Me limitaré a recoger dos de las aportaciones que me parecen más sugerentes y fértiles para el aula de L2. Mercer (2004) describe la actividad de enseñanza-aprendizaje como una conversación en el aula. 
En una aplicación de este género de discurso al contexto de aula, señala cómo toda conversación particular no es sino un fragmento episódico de una conversación mucho más extensa que la persona mantiene con sus interlocutores; en efecto, aparte del contexto situacional momentáneo, toda conversación, también la del aula, se apoya en un contexto cognitivo compartido que los interlocutores han creado en sus intercambios conversacionales anteriores. Estas conversaciones de aula pueden adoptar, según Mercer, tres formas distintas: la conversación en disputa, la conversación en acopio y la conversación en exploración. Si la primera es contraproducente por cuanto no favorece ni construcción conjunta de conocimientos ni interacción, la segunda es estéril pues se limita a acumular acríticamente las distintas intervenciones de los participantes. La más interesante es la exploratoria, pues en ella todo el mundo se ve alentado a contribuir con sus aportaciones, que sin embargo deben estar razonadas y abiertas a la crítica.

Van Lier (1993) describe las distintas posibilidades en que puede darse la interacción entre profesores y alumnos mediante un conjunto de parámetros que le permiten clasificarla en sucesivos grados, desde el modelo de la transmisión, en el que el profesor suministra un cuerpo de conocimientos para que los alumnos los reciban y los incorporen, hasta el de la transformación, en el que el profesor presta el apoyo necesario para que las competencias y conocimientos de los alumnos alcancen su mejor desarrollo. El comportamiento que permite avanzar del modelo más pobre al más rico es el que se basa en un discurso del profesor que Van Lier caracteriza como contingente, es decir, orientado a la actividad de los alumnos y dependiente de ella, y que para serlo debe reunir una serie de condiciones, entre las que destaca la de consistir en una interacción conversacional y no monologada.

Para mejor observar estas propiedades del discurso del aula, presentaré y comentaré brevemente un fragmento de una clase de español como lengua extranjera. El fragmento se inserta en una tarea comunicativa en la que los alumnos, trabajando en pequeños grupos, deben elegir un regalo para una determinada persona. Uno de ellos ha propuesto comprar un pañuelo y la interacción prosigue en estos términos:

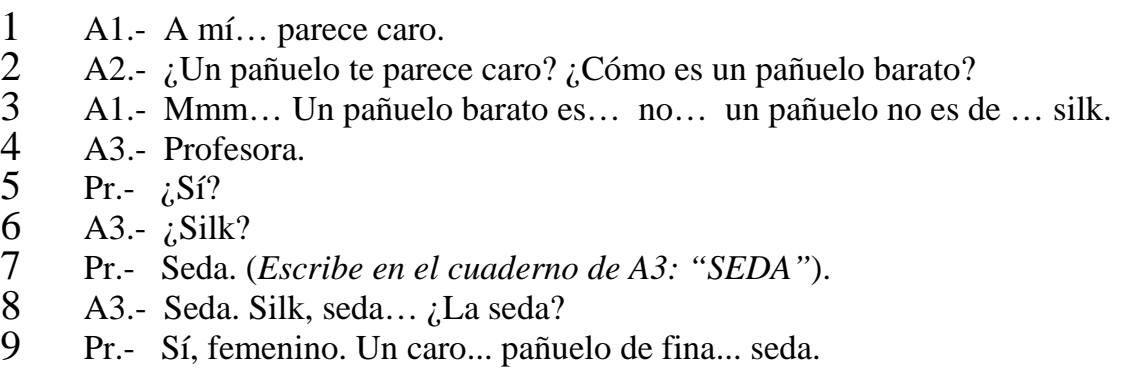


10 A1.- Un pañuelo barato es un pañuelo no es de fina seda.

11 Pr.- Un pañuelo barato es un pañuelo QUE no es de fina seda.

12 A1.- Un pañuelo barato es un pañuelo que no es de fina seda.

13 Pr.- Muy bien, seguid.

14 A2.- Mmm.. ¿ ¿Un pañuelo de seda? ¿Cómo, un pañuelo de seda?

15 A3.- ¿Quieres decir... mm... un pañuelo para la cabeza o para... la... nariz?

16 A1.- [Un pañuelo para la nariz.

17 A2.- [Un pañuelo para la cabeza.

18 risas

Podemos distribuir en tres episodios este breve fragmento:

En el primero, que comprende las líneas 1-3 (1. 1-3), dos alumnos intentan negociar el significado de la primera intervención de uno de ellos (A1). Su atención está centrada en el contenido de su mensaje e intentan ponerse de acuerdo sobre una discrepancia que no saben exactamente dónde reside. A2 quiere saber qué es para A1 un pañuelo barato, pues no se imagina que tal objeto pueda ser caro. Al final de su segunda intervención, A1 recurre al inglés para explicarse, en la confianza de que A2 le entenderá. En todo este episodio, los alumnos han estado usando la L2 como lo harían los nativos fuera de un aula (excepto en lo referente, lógicamente, a la corrección lingüística de sus enunciados). La profesora, aparentemente, no ha intervenido, pese a que las producciones de los alumnos podrían haberle inducido a hacerlo, por su carácter imperfecto o ambiguo.

La conversación podría haber proseguido en l. 14 (sustituyendo aquí "seda" por "silk”), de no ser porque A3 ha decidido que quiere aprender la palabra española para "silk". Con ello se inicia un largo episodio (líneas 4-13), en el que la L2 adquiere nuevas funciones relacionadas con el aprendizaje, pero también, y esto es muy importante, con el logro de la comunicación iniciada en el episodio anterior. Veamos más de cerca las intervenciones de los distintos participantes:

En 1.4, A3 reclama la ayuda de la profesora para conocer el término equivalente del inglés “silk” en español, así como su género gramatical. Es un objetivo que podría haber logrado igualmente con la ayuda de un diccionario, pero legítimamente ha optado por una vía más rápida. La conversación con la profesora es de una gran eficacia por las elipsis sintácticas que A3 se permite, en aras precisamente de la eficacia. Obsérvese, sin embargo, la línea 8: las tres primeras palabras de esta frase no están dirigidas a la profesora, A3 se las dice a sí misma, como apropiándose esas palabras y su significado. Solo al formular la pregunta que cierra su turno está hablando con la profesora. 
Algo parecido, aunque no exactamente igual, lo observamos en las intervenciones de A1 en este episodio. ¿Con quién está hablando este alumno en l. 10 y 12? ¿Qué está diciendo, a quién se lo está diciendo y por qué lo dice? Probablemente está respondiendo a la pregunta inicial de A2 en 1. 2; pero si está haciendo eso, debemos admitir que ese contenido ya se lo había trasladado en la línea 3; estaría, por tanto, formulando un enunciado de forma redundante, y en tal caso deberíamos preguntarnos cuál es la función comunicativa de esa redundancia. Ciertamente, el alumno está aquí apropiándose de los recursos que acaba de facilitarle la profesora; es probable que al mismo tiempo le esté demostrando a la profesora que es un alumno aplicado y listo, que aprende lo que le enseña. Pero en cualquier caso, está haciendo un uso muy particular del lenguaje, con vistas a aprender la L2. Está repitiendo estructuras y formas lingüísticas, pero — a diferencia de las prácticas repetitivas de la enseñanza de corte conductista y estructuralista - lo está haciendo en un marco de conversación sobre un tema y un propósito comunes y —lo que es más importante- lo está haciendo por iniciativa propia y con sus propias intenciones, sin que nadie se lo diga.

Dentro de este episodio podemos detenernos también en las intervenciones de la profesora: en las líneas 5 y 7 responde al requerimiento de A3, y lo hace en un estilo y con unas estrategias orientadas a la eficacia semejantes a las de la alumna. Pero, consciente de cuál es la necesidad concreta de esta (el conocimiento léxico) refuerza su información escribiéndole la palabra en su cuaderno: una muestra breve pero muy rica del recurso de la profesora a la multimodalidad en el uso del lenguaje; de forma análoga, su respuesta en la línea 9 se apoya en otros recursos con miras a la eficacia: a la pregunta de la alumna, que ha optado por el uso del artículo como señal de reconocimiento del género, la profesora responde con la categoría gramatical (“femenino”), acompañada de un ejemplo de contraste de género en nombres, por cierto, muy bien elegidos para el tema que se está tratando.

A esta información lingüística de la profesora sigue la intervención de A1 que ya hemos comentado, y la profesora replica con una intervención, escueta pero compleja: por un lado, sanciona la corrección de la frase que acaba de formular A1, quien ha incorporado todos los datos lingüísticos que le ha proporcionado la profesora y ha logrado formular la frase con plena corrección. Por otro lado, cierra este episodio centrado en la forma lingüística e indica a los alumnos que prosigan con el desarrollo de la tarea.

El tercer episodio comienza con la intervención de A2 (l. 14). En ella, este alumno sigue la instrucción de la profesora y retoma el tema sobre el que venían hablando; al hacerlo, propone 
de nuevo una negociación del sentido de la intervención que acaba de hacer A1 en la línea 12. Obsérvese, por tanto, que A2 ha recibido esta intervención de A1 en su doble valor: no solo como manifestación de la apropiación de los recursos lingüísticos que le ha facilitado la profesora, sino también como expresión de un mensaje que A1 quiere transmitir y que no lo logra plenamente. Hay algo en el léxico de A1 que lo desconcierta y que no acaba de casar con el conocimiento del mundo que tiene. A3 acude otra vez en ayuda del grupo, desde su conocimiento de los dos significados de la palabra "pañuelo": como prenda de bolsillo para limpiarse la nariz, o como accesorio de la indumentaria que se pone en la cabeza; resuelve así la ambigüedad del término, que originaba el desencuentro comunicativo entre sus dos compañeros, como se pone de manifiesto en las dos últimas intervenciones y en las risas finales.

\section{Recapitulación}

Vemos cómo un fragmento tan breve de una clase de L2 proporciona abundantes muestras de la diversidad de funciones que la lengua desempeña efectivamente en un proceso de aprendizaje eficaz, y de la naturalidad con que los participantes en la sesión recurren a esas diversas funciones. Es tarea nuestra, en cuanto investigadores, profundizar en el conocimiento de esas funciones y de sus diversas manifestaciones; y, en cuanto profesores, saber responder adecuadamente a esta realidad de la presencia de las lenguas en nuestras aulas, con vistas a una mejor explotación de todas sus virtudes.

\section{Referencias Bibliográficas}

Bange, P. (1992) A propos de la communication et de l'apprentissage de L2 (notamment dans ses formes institutionelles), Aile, 1, 53-85.

Bruner, J. (1966) Toward a theory of instruction. Harvard: Harvard University Press.

Consejo de Europa (2001) Marco común europeo de referencia para las lenguas. Aprendizaje, enseñanza, evaluación http://cvc.cervantes.es/ensenanza/biblioteca_ele/marco/default.htm (Consultado en fecha 31/05/2010).

Donato, R. (1994) Collective scaffolding in second language learning. En Lantolf J.P. y G. Appel, Vygotskyian approaches to second language research, pp. 33-56. Norwood, NJ: Ablex Publishing Corporation.

Halliday, M.A.K. (1993) Towards a language-based theory of learning. Linguistics and Education, 5, 93-116.

Koch, P. y Oesterreicher, W. (2007) Lengua hablada en la Romania: español, francés, italiano. Madrid: Gredos.

Lantolf, J.P. (ed.) (2000) Sociocultural theory and second language learning. Oxford/ New York: Oxford University Press. 
Lantolf J.P. y G. Appel (Eds.), Vygotskian approaches to second language learning. Norwood, NJ: Ablex Publishing Corporation.

Llobera, M. (1990) Reconsideración del discurso interactivo en la clase de L2 o LE. Comunicación, Lenguaje y Educación, Vol. 7-8, 91-98.

Mercer, N. (2004) Sociocultural discourse analysis: analysing classroom talk as a social mode of thinking. Journal of Applied Linguistics, 1/2, 137-168.

van Lier, L.. (1996) Interaction in the language curriculum: Awareness, autonomy \& authenticity. Cambridge: Cambridge University Press.

Vygotsky, L. (1978) Mind in society: The development of higher psychological processes. Cambridge (MA): MIT Press.

Wells, G. (1994) The complementary contributions of Halliday and Vygotsky to a 'languagebased theory of learning'. Linguistics and Education, 6, 41-90.

Widdowson, H.G. (1978) Teaching language as communication. Cambridge: Cambridge University Press.

Referencia del autor:

Ernesto Martín Peris es Profesor Emérito de Llengua Espanyola en la Universitat Pompeu Fabra. Miembro fundador de GR@EL (Grup de recerca sobre aprenentatge i ensenyament de llengües), también es profesor de Metodología del Máster Oficial Interuniversitario (UPF-UB) en Formación de Profesores de Español como Lengua Extranjera (ELE). El Dr. Martín Peris es director y profesor de numerosos cursos de formación de profesorado de ELE, y profesor invitado en másters y doctorados sobre aprendizaje de lenguas. Es autor de diversos libros para la enseñanza de ELE y la formación del profesorado: Gente (Difusión, 2000); Para empezar, (Edi-6, 1984); Profesor en acción, (Edelsa, 1994). Recientemente ha dirigido el Diccionario de términos clave de Español como Lengua Extranjera (SGEL, 2008). Ha sido director académico del Instituto Cervantes; miembro del Consejo Asesor de los “Diplomas de Español como Lengua Extranjera” del Ministerio de Educación; catedrático de Español como Lengua Extranjera de l’Escola Oficial d’Idiomes de Barcelona, de la que también fue director.

Email: ernesto.martin@upf.edu

1 NB (Editora): Este artículo procede de la Conferencia de Clausura de las Jornadas Interuniversitárias UAB/UB/UPF (Universitat Pompeu Fabra, 26/03/10).

2 Es preciso añadir que no siempre se ha distinguido con suficiente nitidez el uso de la lengua oral en el aula como medio o canal, y su uso como modo de comunicación. No ha sido infrecuente realizar prácticas pretendidamente de comunicación oral consistentes en la formulación oral de frases más propias de la comunicación escrita. A este respecto, puede consultarse con provecho Koch y Oesterreicher (2007) Lengua hablada en la Romania: español, francés, italiano. En su aplicación a la enseñanza de lenguas, H. G. Widdowson (1978) Teaching Language as Communication supone una valiosa aportación.

3 http://cvc.cervantes.es/foros/leer.asp?vId=105285

4 http://www.upf.edu/dtf/recerca/grups/grael/LC/index.html

5 Entre nosotros cabe destacar las aportaciones de M. Llobera (1990). 